\title{
Crescimento e floração do girassol sob estresse salino e adubação nitrogenada ${ }^{1}$
}

\author{
Growth and flowering of sunflower under saline stress and nitrogen fertilization
}

\author{
Reginaldo Gomes Nobre ${ }^{2 *}$, Hans Raj Gheyi ${ }^{3}$, Karina Guedes Correia ${ }^{4}$, Frederico Antonio Loureiro Soares ${ }^{4}$ e \\ Leandro Oliveira de Andrade ${ }^{4}$
}

\begin{abstract}
Resumo - Considerando a importância do girassol (Helianthus annuus L.) como fonte potencial de energia renovável e a carência de resultados de pesquisas relativos a seu cultivo, avaliaram-se com este trabalho variáveis de crescimento e de floração do girassol cv. Embrapa 122/V-2000 sob diferentes níveis de salinidade da água de irrigação (CEa) e doses de adubação nitrogenada, em experimento conduzido em ambiente protegido da UFCG, entre julho e outubro de 2009. Usouse a aleatorização em bloco, testando 5 níveis de salinidade da água de irrigação $\left(0,5\right.$ - controle; 1,$6 ; 2,7 ; 3,8$ e $\left.4,9 \mathrm{dS} \mathrm{m}^{-1}\right)$ e 4 doses de adubação nitrogenada (50; 75; 100 e 125\% da dose indicada para ensaio em vaso), em esquema fatorial $5 \times 4$, com 3 repetições. O aumento da $\mathrm{CEa}$ a partir de $0,5 \mathrm{dS} \mathrm{m}^{-1}$ promoveu redução na altura de planta, no diâmetro caulinar, na fitomassa seca da parte aérea, e nos diâmetros externo e interno do capítulo, além de retardar o início do florescimento das plantas. O diâmetro interno do capítulo, por ter sido a variável mais afetada pela salinidade, com redução linear de 7,6\%

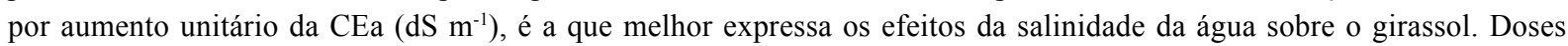
de nitrogênio variando de 0,46 a $0,64 \mathrm{~g} \mathrm{~kg}^{-1}$ de solo não promoveram efeito significativo sobre as variáveis estudadas de crescimento e floração do girassol cv. Embrapa 122/V-2000.
\end{abstract}

Palavras-chave - Helianthus annuus L. Condutividade elétrica. Solos-salinidade. Energia-fontes alternativas. Biocombustíveis.

\begin{abstract}
Considering the importance of the sunflower (Helianthus annuus L.) as a potential source of renewable energy and the lack of information regarding its cultivation. In this study the growth variables and flowering of sunflower cv. Embrapa 122/V-2000 were evaluated under different levels of salinity of irrigation water (ECw) and doses of nitrogen. The experiment was conducted in protected environment at UFCG, between July and October 2009. Randomized block design was used to test 5 levels of salinity of irrigation water - ECw $\left(0.5\right.$ - control, $1.6 ; 2.7 ; 3.8$ and $\left.4.9 \mathrm{dS} \mathrm{m}^{-1}\right)$ and 4 doses of nitrogen $(50 ; 75 ; 100$ and $125 \%$ of nitrogen recommended for pot experiment) in $5 \times 4$ factorial scheme, with 3 replications. The increase of $\mathrm{ECW}$ from $0.5 \mathrm{dS} \mathrm{m} \mathrm{m}^{-1}$ promoted reduction in plant height, stem diameter, dry biomass of aerial parts, external and internal diameter of head, in addition to delay in flowering of plants. The internal diameter of head was most affected by salinity with a linear reduction of $7.6 \%$ for unit increase of $\mathrm{ECw}\left(\mathrm{dS} \mathrm{m} \mathrm{m}^{-1}\right)$ and is the variable which best expresses the effects of water salinity on the sunflower. Nitrogen doses ranging from 0.46 to $0.64 \mathrm{~g} \mathrm{~kg}^{-1}$ of soil did not affect significantly the studied variables' of growth and flowering of sunflower cv. Embrapa 122/V-2000.
\end{abstract}

Key words - Helianthus annuus L. Electrical conductivity. Soil-salinity. Energy-alternative sources. Biofuels.

\footnotetext{
* Autor para correspondência

${ }^{1}$ Recebido para publicação em 07/11/2009; aprovado em 05/07/2010

Projeto de pesquisa de Pós-Doutorado Junior / CNPq / INCTSal

${ }^{2}$ Centro de Ciência e Tecnologia Agroalimentar, UAGRA/UFCG, Rua Newton Seixas, 333, Bairro Jardim Rogério, Pombal-PB, Brasil, 58.840-000, rgomesnobre@yahoo.com.br

${ }_{3}^{3}$ Departamento de Eng. Agrícola, CTRN/UFCG, atualmente Professor Visitante UFRB, hans@deag.ufcg.edu.br

${ }^{4}$ Programa de Pós-Graduação em Engenharia Agrícola, CTRN/UFCG, Campina Grande-PB, Brasil, correiakg@gmail.com, fredalsoares@hotmail. com, leandro.ufcg@hotmail.com
} 


\section{Introdução}

O girassol (Helianthus annuus L.) pertencente à família Asteraceae está inserido entre as espécies vegetais de maior potencial para a produção de biocombustível, além de se constituir em uma importante opção para o produtor agrícola em sistemas envolvendo rotação ou sucessão de culturas. Sua ampla adaptação as diferentes condições climáticas, teor e qualidade do óleo de suas sementes, contribuirão com a inserção da mesma no programa nacional de produção e uso de biodiesel (UNGARO, 2006).

Na safra brasileira de 2008 foram cultivados cerca de 108.979 ha com girassol, com rendimento médio de $1.337 \mathrm{~kg} \mathrm{ha}^{-1} \mathrm{e}$, para a safra 2009, existe previsão de que o rendimento alcance $1.500 \mathrm{~kg} \mathrm{ha}^{-1}$ (IBGE, 2009).

A nutrição mineral é um importante fator ambiental, sendo o nitrogênio o macronutriente exigido em maior quantidade pelas culturas agrícolas (MILLER; CRAMER, 2004). Esta alta dependência ocorre devido às funções do $\mathrm{N}$ no metabolismo das plantas, participando como constituinte da molécula de clorofila, ácidos nucléicos, aminoácidos e proteínas. O $\mathrm{N}$ tem como principal fonte o nitrato, sendo esta mais abundante do que o amônio $\left(\mathrm{NH}_{4}^{+}\right)$em torno das raízes. Entretanto, a solução do solo frequentemente apresenta baixas concentrações de $\mathrm{NO}_{3}$, o que limita o crescimento da planta (FLORES et al., 2002).

O conhecimento do teor médio de sais na zona radicular, tolerável pelas plantas, sem afetar significativamente seus rendimentos, pode favorecer a utilização de águas com certo grau de salinidade, tão comuns no Nordeste brasileiro. Nesse sentido devem ser realizados estudos visando à obtenção de índices de tolerância das culturas à salinidade, propiciando o estabelecimento do grau de restrição das águas para irrigação (STEPPUHN, 2001).

A salinidade inibe o crescimento das plantas em função dos efeitos osmóticos dos sais e, aos efeitos específicos dos íons. Entretanto, tais efeitos dependem de muitos outros fatores, como espécie, cultivar, estádio fenológico, características dos sais, intensidade e duração do estresse salino, manejo cultural e da irrigação e condições edafoclimáticas (ASHRAF; HARRIS, 2004; TESTER; DAVENPORT, 2003).

Em geral, a salinização dos solos ocorre com a acumulação de determinadas espécies iônicas, sendo o $\mathrm{Na}^{+}$e $\mathrm{Cl}^{-}$os mais frequentes e são considerados os principais íons a prejudicar o metabolismo das plantas. A predominância desses íons no meio de crescimento radicular pode causar toxidez quando eles se acumulam nos tecidos vegetais, acarretar mudanças na capacidade da planta em absorver, transportar e utilizar os íons necessários ao seu crescimento. Assim, deficiências de $\mathrm{Ca}^{2+}$ podem ser induzidas por excesso de $\mathrm{Na}^{+}$, deficiências de $\mathrm{K}^{+}$por excesso de $\mathrm{Na}^{+}$ou $\mathrm{Ca}^{2+}$, altas concentrações de $\mathrm{Mg}^{2+}$ podem inibir a absorção de $\mathrm{K}^{+}$ou de $\mathrm{Ca}^{2+}$ (MARSCHNER, 2002) além de concentração salina alta no meio, afetar a absorção de nitrato $\left(\mathrm{NO}_{3}^{-}\right)$e a assimilação de nitrogênio necessário à síntese protéica (DEBOUBA et al., 2006).

A pesquisa teve como objetivo avaliar o crescimento e floração do girassol em função da concentração salina das águas e de adubação nitrogenada.

\section{Material e métodos}

O experimento foi conduzido em vasos sob ambiente protegido (casa de vegetação) pertencente à Unidade Acadêmica de Engenharia Agrícola da Universidade Federal de Campina Grande (UFCG), Campina Grande, PB, entre julho e outubro de 2009. O local possui as seguintes coordenadas geográficas: $7^{\circ} 15^{\prime} 18^{\prime \prime}$ de latitude Sul, 35'52'28" de longitude Oeste e altitude de $550 \mathrm{~m}$; conforme a classificação climática de Köppen, adaptada ao Brasil (COELHO; SONCIN, 1982), o clima da região é do tipo Csa, que representa clima mesotérmico, sub úmido, com período de estiagem quente e seco (4 a 5 meses) e período chuvoso de outono a inverno.

Os tratamentos resultaram da combinação de dois fatores: salinidade da água de irrigação $(\mathrm{CEa})$ em cinco níveis $\left(0,5\right.$ - controle; 1,$6 ; 2,7 ; 3,8$ e $\left.4,9 \mathrm{dS} \mathrm{m}^{-1}\right)$ e quatro doses de adubação nitrogenada $(50 ; 75 ; 100$ e $125 \%$ da indicação de adubação nitrogenada para ensaio em vaso conforme (NOVAIS et al., 1991), correspondendo a $0,96 \mathrm{~g}$ de uréia e $1,47 \mathrm{~g}$ de nitrato de potássio). As unidades experimentais foram dispostas em fileira dupla espaçadas de 1,0 m entre fileiras duplas, 0,6 m entre fileiras e $0,6 \mathrm{~m}$ entre plantas dentro da fileira dupla.

As águas de diferentes salinidades foram obtidas a partir da adição de cloreto de sódio $(\mathrm{NaCl})$ a água de abastecimento, calculadas conforme a equação $\mathrm{C}$ $\left(\mathrm{mg} \mathrm{L}^{-1}\right)=640 \times \mathrm{CEa}\left(\mathrm{dS} \mathrm{m}{ }^{-1}\right)($ RICHARDS, 1954). A adubação nitrogenada foi dividida em cinco parcelas e aplicada em intervalos de dez dias a partir de dez dias após semeadura (DAS). Sementes de girassol, variedade Embrapa 122/V-2000, foram fornecidas pela Embrapa Soja. Segundo Embrapa (2006) este material genético destaca-se pela precocidade, produtividade, qualidade e teor de óleo nos aquênios.

Utilizaram-se no experimento vasos plásticos de $23 \mathrm{~L}$ de capacidade, preenchidos com $0,8 \mathrm{~kg}$ de brita $\left(\mathrm{n}^{\mathrm{o}}\right.$ zero) a qual cobria a base do vaso seguida de $1,0 \mathrm{~kg}$ de areia lavada e $21 \mathrm{~kg}$ de material de solo denominado 
Neossolo Regolítico Eutrófico textura franco-arenoso, não salino e não sódico, proveniente do município de Campina Grande, PB. As características físico-químicas do solo utilizado (TAB. 1) foram determinadas conforme metodologia recomendada pela Embrapa (1997). Os vasos possuíam furos na base para permitir a drenagem e abaixo dos mesmos existia uma bandeja plástica contendo um microtubo (12 $\mathrm{mm}$ de diâmetro) conectando a sua base a um recipiente de 1,5 L de capacidade, para acompanhamento do volume drenado visando quantificar o consumo de água da cultura.

O solo antes de ser acondicionado no vaso foi submetido à desinfecção usando brometo de metila (uma pastilha por $\mathrm{m}^{3}$ ), deixando-se o mesmo coberto com lona plástica durante 72 horas. Posteriormente fez-se adubação básica com $420 \mathrm{~g}$ de vermicomposto e $13 \mathrm{~g}$ de superfosfato simples por vaso.

Antes da semeadura, determinou-se o volume de água necessária para o solo atingir a capacidade de campo, através do método de saturação por capilaridade seguida por drenagem livre. Foram semeadas em 27 de julho de 2009, 12 sementes de girassol por vaso a $0,04 \mathrm{~m}$ de profundidade e distribuídas de forma equidistantes.

A emergência das plântulas iniciou no terceiro DAS e continuou até o décimo dia, sendo que, neste dia foi realizado o primeiro desbaste, deixando-se apenas três plantas por vaso (até 26 DAS), as de melhor vigor. Aos 20 e 26 DAS foram realizados novos desbastes, onde se eliminou em cada um, uma planta por vaso.

As irrigações eram realizadas ao final da tarde segundo um turno de rega de três dias a partir do semeio até os 22 DAS onde aplicava-se um volume de $300 \mathrm{~mL}$ por vaso. Posteriormente, o turno de rega foi reduzido para dois dias e o volume de água aplicado nestas irrigações foi em base de um ensaio anterior (NOBRE et al., 2009) em que levaram em consideração o balanço de água no sistema radicular.

Durante a condução do experimento foram realizados os seguintes tratos culturais: eliminavam-se manualmente as plantas daninhas, realizava antes de cada irrigação, a escarificação superficial do solo, fez-se o tutoramento das plantas além de pulverizações, a cada 30 dias, com produtos indicados para controle preventivo de insetos e doenças fungicas.

Para análise do efeito dos tratamentos foram mensurados, aos 26 e 50 DAS, o número de folhas (NF), a altura de planta (AP) e o diâmetro do caule (DC) e aos 20 e 26 DAS à fitomassa seca da parte aérea (FSPA). Determinou-se ainda o início do florescimento (IF) e os diâmetros externo (DCe) e interno (DCi) do capítulo.
Tabela 1 - Características físicas e químicas do solo utilizado no experimento

\begin{tabular}{|c|c|}
\hline Característica & Valor \\
\hline Classificação textural & Franco-arenoso \\
\hline Densidade aparente $-\mathrm{kg} \mathrm{dm}^{-3}$ & 1,45 \\
\hline Porosidade - \% & 42,35 \\
\hline Capacidade de campo - $\mathrm{g} \mathrm{kg}^{-1}$ & 83,60 \\
\hline Ponto de murchamento - $\mathrm{g} \mathrm{kg}^{-1}$ & 22,90 \\
\hline Água disponível - $\mathrm{g} \mathrm{kg}^{-1}$ & 60,70 \\
\hline \multicolumn{2}{|l|}{ Complexo sortivo $\left(\mathrm{cmol}_{\mathrm{c}} \mathrm{kg}^{-1}\right)$} \\
\hline Cálcio $\left(\mathrm{Ca}^{2+}\right)$ & 1,87 \\
\hline Magnésio $\left(\mathrm{Mg}^{2+}\right)$ & 1,05 \\
\hline Sódio $\left(\mathrm{Na}^{+}\right)$ & 0,06 \\
\hline Potássio $\left(\mathrm{K}^{+}\right)$ & 0,23 \\
\hline $\mathrm{pH}_{\mathrm{ps}}$ & 6,15 \\
\hline $\mathrm{CE}_{\mathrm{es}}-\mathrm{dS} \mathrm{m} \mathrm{m}^{-1}$ & 0,51 \\
\hline \multicolumn{2}{|l|}{ Extrato de saturação $\left(\mathrm{mmol}_{\mathrm{c}} \mathrm{L}^{-1}\right)$} \\
\hline Cloro $\left(\mathrm{Cl}^{-}\right)$ & 3,75 \\
\hline Carbonato $\left(\mathrm{CO}_{3}^{2-}\right)$ & Ausente \\
\hline Bicarbonato $\left(\mathrm{HCO}_{3}^{-}\right)$ & 1,70 \\
\hline Sulfato $\left(\mathrm{SO}_{4}^{2-}\right)$ & Presente \\
\hline Cálcio $\left(\mathrm{Ca}^{2+}\right)$ & 1,75 \\
\hline Magnésio $\left(\mathrm{Mg}^{2+}\right)$ & 2,00 \\
\hline Sódio $\left(\mathrm{Na}^{+}\right)$ & 1,12 \\
\hline Potássio $\left(\mathrm{K}^{+}\right)$ & 0,55 \\
\hline
\end{tabular}

$\mathrm{Na}$ contagem do número de folhas consideraram-se as que estavam totalmente expandidas com comprimento mínimo de $2 \mathrm{~cm}$; a AP foi definida mensurando-se a distância entre o colo da planta e a inserção da folha mais nova e o DC foi medido a $5 \mathrm{~cm}$ do colo da planta. No início do florescimento foi mensurado o momento (dia) em que a planta encontrava-se no estádio fenológico $\mathrm{R}_{4}$ (CONNOR; HALL, 1997), ou seja, começo da abertura da inflorescência e, durante o estádio $\mathrm{R}_{5}$ (inflorescência completamente aberta), mensurou-se o DCe e o DCi. Na colheita, a haste de cada planta foi cortada rente ao solo e após secagem em estufa com ventilação forçada de ar, a $65^{\circ} \mathrm{C}$, até a obtenção de peso constante, determinou-se a FSPA.

Os dados obtidos foram avaliados mediante análise de variância pelo teste ' $\mathrm{F}$ ' ao nível de 0,05 de 
probabilidade e nos casos de significância, realizou-se análise de regressão polinomial linear, quadrática e cúbica utilizando do software estatístico SISVAR-ESAL (Lavras, MG) (FERREIRA, 2003). Em função da homogeneidade dos dados percebido através dos baixos valores de coeficiente de variação (TAB. 2 e 3), não foi necessário realizar análise exploratória dos dados.

\section{Resultados e discussão}

Verifica-se com base nos resultados da análise de variância (TAB. 2 e 3) dos dados, não haver efeito significativo pelo teste $\mathrm{F}$ na interação entre os fatores estudados (salinidade da água de irrigação e doses de adubação nitrogenada) para nenhuma variável analisada, o que indica que as doses de $\mathrm{N}$ comportaram de maneira semelhante em diferentes níveis de salinidade da água utilizada na irrigação. Oliveira et al. (2006) analisando os efeitos da irrigação com água de diferentes salinidades e teores de esterco bovino no crescimento inicial da mamoneira observaram também não haver interação entre os fatores.

Apesar da variação das doses de adubação nitrogenada $\left(9,76 \mathrm{a} 13,39 \mathrm{~g} \mathrm{deN}\right.$ vaso $\left.^{-1}\right)$ fornecida as plantas, não foram constatadas ocorrência de efeito significativo (TAB. 2 e 3 ) sobre as variáveis estudadas, denotando que a quantidade de $\mathrm{N}$ contido no vermicomposto (adubação de plantio) disponibilizaram quantidades satisfatórias de nitrogênio ao girassol. Outrossim, a salinidade da água pode ter comprometido a absorção de $\mathrm{N}$ devido a competição iônica nos sítios de adsorção. Conforme Bosco et al. (2009) plantas cultivadas sob salinidade tendem a absorver menos nitrogênio enquanto que os níveis de $\mathrm{Cl}^{-}$ absorvidos e acumulados são acrescidos.

Carvalho e Pissaia (2002) avaliando o efeito de diferentes doses de nitrogênio (0 a $\left.125 \mathrm{~kg} \mathrm{ha}^{-1} \mathrm{de} \mathrm{N}\right) \mathrm{em}$ cobertura no cultivo do girassol em sistema plantio direto na palha não constataram efeito significativo da adubação sobre o rendimento de grãos, seus componentes, o índice de colheita aparente e teor de óleo nos aquênios de girassol. Já Biscaro et al. (2008) encontraram resultados diferentes ao estudarem a aplicação parcelada de nitrogênio em cobertura ( 0 a $80 \mathrm{~kg} \mathrm{ha}^{-1}$ de $\left.\mathrm{N}\right)$ sobre a cultura do girassol em condição de campo, onde obtiveram incremento do NF, AP, DC e variáveis de produção, sendo alcançando com a dose de $55 \mathrm{~kg} \mathrm{ha}^{-1}$ de $\mathrm{N}$ a máxima eficiência para produção.

De acordo com a análise de variância (TAB. 2), o número de folhas não variou significativamente conforme o teste $\mathrm{F}$ em função dos diferentes níveis de salinidade da água de irrigação, em avaliações realizadas aos 26 e 50 DAS. Cavalcanti et al. (2004) analisando o crescimento inicial da mamoneira submetida a diferentes níveis de salinidade da água de irrigação $\left(0,7\right.$ a 4,7 dS m $\left.{ }^{-1}\right)$ também não observaram efeito significativo da salinidade sobre esta variável. Já Travassos et al. (2009) estudando o crescimento inicial de girassol cv. Embrapa 122/V-2000 sob CEa variando de 1 a $5 \mathrm{dS} \mathrm{m}^{-1}$, constataram aos $28 \mathrm{DAS}$, decréscimo linear do NF com o aumento da salinidade da água.

Tabela 2 - Resumo da análise de variância para número de folha (NF), altura de planta (AP) e diâmetro de caule (DC) aos 26 e 50 dias após o semeio (DAS) do girassol em função de diferentes níveis de salinidade da água de irrigação e doses de nitrogênio

\begin{tabular}{|c|c|c|c|c|c|c|}
\hline \multirow{3}{*}{ Fonte de Variação } & \multicolumn{6}{|c|}{ Quadrado Médio } \\
\hline & \multicolumn{2}{|c|}{$\mathrm{NF}$} & \multicolumn{2}{|c|}{$\mathrm{AP}(\mathrm{cm})$} & \multicolumn{2}{|c|}{$\mathrm{DC}(\mathrm{mm})$} \\
\hline & $26 \mathrm{DAS}$ & $50 \mathrm{DAS}$ & $26 \mathrm{DAS}$ & 50 DAS & $26 \mathrm{DAS}$ & 50 DAS \\
\hline Níveis salino (S) & $6,81^{\text {ns }}$ & $10,69^{\text {ns }}$ & $64,77 * *$ & $1871,07 * *$ & $1,27 * *$ & $14,43^{* *}$ \\
\hline Reg. Linear & $5,63^{\mathrm{ns}}$ & $34,13^{\mathrm{ns}}$ & $234,92 * *$ & $7324,22 * *$ & $4,49 * *$ & $54,77 * *$ \\
\hline Reg. Quadrática & $5,36^{\mathrm{ns}}$ & $8,60^{\mathrm{ns}}$ & $0,32^{\mathrm{ns}}$ & $102,93^{\mathrm{ns}}$ & $0,55^{\mathrm{ns}}$ & $1,18^{\mathrm{ns}}$ \\
\hline Reg. Cúbica & $14,70^{\mathrm{ns}}$ & $0,03^{\text {ns }}$ & $1,14^{\mathrm{ns}}$ & $56,72^{\mathrm{ns}}$ & $0,04^{\mathrm{ns}}$ & $0,27^{\mathrm{ns}}$ \\
\hline Doses nitrogênio (D) & $1,38^{\mathrm{ns}}$ & $8,99^{\mathrm{ns}}$ & $20,92^{\mathrm{ns}}$ & $148,86^{\mathrm{ns}}$ & $0,24^{\mathrm{ns}}$ & $0,44^{\mathrm{ns}}$ \\
\hline Reg. Linear & $0,21^{\mathrm{ns}}$ & $7,36^{\mathrm{ns}}$ & $11,02^{\mathrm{ns}}$ & $420,08^{\mathrm{ns}}$ & $0,68^{\mathrm{ns}}$ & $0,98^{\mathrm{ns}}$ \\
\hline Reg. Quadrática & $3,27^{\mathrm{ns}}$ & $2,82^{\mathrm{ns}}$ & $41,83^{\text {ns }}$ & $2,40^{\mathrm{ns}}$ & $0,03^{\text {ns }}$ & $0,13^{\text {ns }}$ \\
\hline Interação (S x D) & $1,03^{\mathrm{ns}}$ & $5,09^{\mathrm{ns}}$ & $6,89^{\mathrm{ns}}$ & $56,35^{\mathrm{ns}}$ & $0,12^{\mathrm{ns}}$ & $0,51^{\mathrm{ns}}$ \\
\hline Bloco & $0,02^{\mathrm{ns}}$ & $11,47^{\mathrm{ns}}$ & $0,13^{\mathrm{ns}}$ & $50,87^{\mathrm{ns}}$ & $0,01^{\mathrm{ns}}$ & $0,22^{\mathrm{ns}}$ \\
\hline $\mathrm{CV}(\%)$ & 13,71 & 11,83 & 8,19 & 7,04 & 8,28 & 8,64 \\
\hline
\end{tabular}

$\mathrm{ns}, * *, *$ respectivamente não significativo, significativo a $\mathrm{p}<0,01$ e $\mathrm{p}<0,05$ pelo teste $\mathrm{F}$ 
Observa-se na Tabela 2, a ocorrência de efeitos significativos $(\mathrm{p}<0,01)$ dos níveis de salinidade da água de irrigação para as variáveis AP e DC das plantas de girassol avaliadas aos 26 e 50 DAS. Conforme equações de regressão (FIG. 1A) referente à altura de planta, o modelo linear indica um decréscimo de $3,1 \%$ $(1,27 \mathrm{~cm})$ e $5,3 \%(7,10 \mathrm{~cm})$ na AP por aumento unitário da condutividade elétrica da água de irrigação, aos $26 \mathrm{e}$ 50 DAS, respectivamente, ou seja, decréscimo de 13,6 e $23,4 \%$ da AP na primeira e segunda época de avaliação nas plantas irrigadas com água de $4,9 \mathrm{dS} \mathrm{m}^{-1}$ em relação as testemunhas. Em função dos poucos trabalhos sobre CEa e girassol, ressaltam-se resultados obtidos com outras oleaginosas em casa de vegetação, Cavalcanti et al. (2004) estudando a influência da salinidade da água de irrigação sobre o crescimento da mamoneira verificaram que o incremento da CEa a partir de $0,7 \mathrm{dS}$ $\mathrm{m}^{-1}$ contribui para a redução da AP; Nery et al. (2009) em trabalho com o pinhão-manso, também verificou redução da AP em função do aumento da $\mathrm{CEa}$, indicando que aos 58 DAS houve decréscimo de $8,6 \%$ na AP quando submeteram-se as plantas a salinidade da água de 3,0 dS m m $^{-1}$ em relação as plantas cultivadas sob salinidade de $0,6 \mathrm{dS} \mathrm{m}^{-1}$.

A salinidade crescente da água de irrigação proporcionou decréscimo linear do diâmetro caulinar do girassol. Analisando as equações de regressão para o DC (FIG. 1B) vê-se decréscimo de 2,7 e $5,0 \%$, ou seja, 0,18 e $0,62 \mathrm{~mm}$ do DC por aumento unitário da condutividade elétrica da água de irrigação, respectivamente, aos 26 e 50 DAS. Vê-se que a CEa afetou de forma mais pronunciada a AP e o DC aos 50 DAS, denotando o efeito da acumulação de sais no solo proveniente das irrigações com o tempo. Conforme Ayers e Westcot (1999), o aumento da pressão osmótica do solo ocasionado pelos íons, atua de forma negativa sobre os processos fisiológicos, reduzindo a absorção de água pelas raízes, inibindo a atividade meristemática e o alongamento celular, advindo, como consequência, a redução no crescimento das plantas.

Denota-se no presente estudo que o aumento da concentração de $\mathrm{NaCl}$ na solução do solo, ocorrido pelo aporte da água de irrigação, tenha contribuído negativamente sobre a absorção de água pelas plantas, o que foi determinante para a redução dos processos fotossintéticos e metabólicos da cultura, de forma a provocar redução da $\mathrm{AP}$ e do $\mathrm{DC}$ à medida em que $\mathrm{CEa}$ foi acrescida. De acordo com Travassos et al. (2009) o aumento da CEa de 1 a $5 \mathrm{dS} \mathrm{m}^{-1}$ promoveu também, decréscimos linear de 0,32 e $2,67 \mathrm{~cm}$ na altura e de 0,15 e 0,62 mm no diâmetro caulinar de plantas de girassol (cv. Embrapa 122/V-2000) em avaliações realizadas aos 18 e 28 DAS, respectivamente, o que indica sensibilidade desta cultivar ao excesso de sais na zona radicular.

Oliveira et al. (2008) trabalhando com cultivares de algodoeiro irrigadas com água de diferentes salinidades $\left(0,5\right.$ a 8,5 dS m $\left.{ }^{-1}\right)$ constataram redução na absorção de água pela cultura com o incremento da $\mathrm{CEa}$ e por consequente, diminuição do crescimento e desenvolvimento das plantas.

A fitomassa seca da parte aérea foi afetada, significativamente $(\mathrm{p}<0,01)$ aos 20 DAS e aos 26 DAS ( $p<0,05)$, pela CEa (TAB. 3). De acordo com os estudos de regressão, o efeito foi linear nas duas épocas de avaliação, havendo decréscimo por aumento unitário da CEa de 5,6 e 5,7\%, ou seja, 0,60 e 1,38 g aos 20 e 26 DAS, respectivamente, ou seja, a produção de massa seca entre $\mathrm{S}_{1}$ e $\mathrm{S}_{5}$ teve redução de $24,5 \%$ na primeira análise e $25,1 \%$ na segunda (FIG. 2) avaliação. Das variáveis de crescimento estudadas nesta pesquisa, a FSPA foi a mais afetada pelo incremento de salinidade da água de
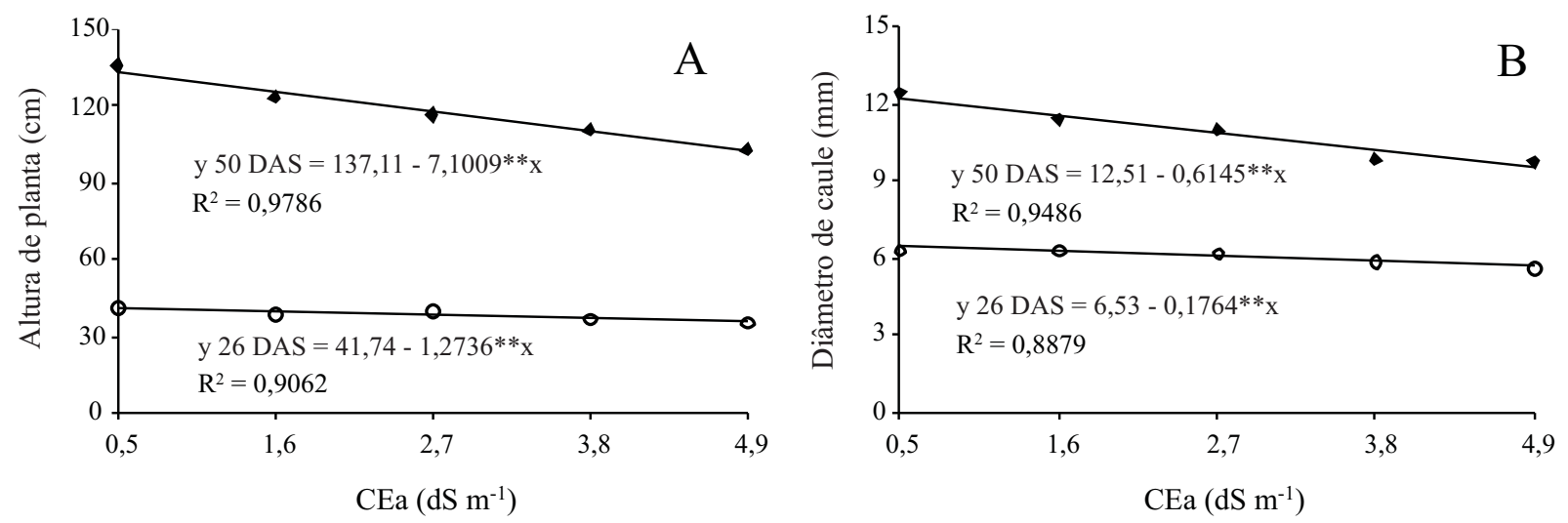

Figura 1 - Altura de planta (A) e diâmetro de caule (B) de plantas de girassol, em função da condutividade elétrica da água de irrigação (CEa), aos 26 e 50 dias após semeadura (DAS) 
Tabela 3 - Resumo da análise de variância para fitomassa seca da parte aérea (FSPA) aos 20 e 26 dias após o semeio (DAS), início do florescimento (IF), diâmetro externo (DCe) e interno (DCi) de capítulo do girassol em função de diferentes níveis de salinidade da água de irrigação e doses de nitrogênio

\begin{tabular}{lccccc}
\hline \multirow{3}{*}{ Fonte de Variação } & \multicolumn{5}{c}{ Quadrado Médio } \\
\cline { 2 - 6 } & \multicolumn{2}{c}{${ }^{1} F S P A(\mathrm{~g})$} & $\mathrm{IF}$ & $\mathrm{DCe}$ & $\mathrm{DCi}$ \\
\cline { 2 - 5 } & $20 \mathrm{DAS}$ & $26 \mathrm{DAS}$ & $\mathrm{d}$ dia $)$ & $(\mathrm{cm})$ & $(\mathrm{cm})$ \\
\hline Níveis salino (S) & $0,032^{* *}$ & $0,056^{*}$ & $27,43^{*}$ & $24,76^{* *}$ & $27,46^{* *}$ \\
Reg. Linear & $0,078^{* *}$ & $0,192^{* *}$ & $97,20^{* *}$ & $85,68^{* *}$ & $105,94^{* *}$ \\
Reg. Quadrática & $0,09^{*}$ & $0,001^{\text {ns }}$ & $6,10^{\text {ns }}$ & $0,02^{\text {ns }}$ & $3,77^{* *}$ \\
Reg. Cúbica & $0,003^{\text {ns }}$ & $0,010^{\text {ns }}$ & $5,63^{\text {ns }}$ & $10,83^{\text {ns }}$ & $0,00^{\text {ns }}$ \\
Doses nitrogênio (D) & $0,002^{\text {ns }}$ & $0,025^{\text {ns }}$ & $11,04^{\text {ns }}$ & $7,87^{\text {ns }}$ & $0,26^{\text {ns }}$ \\
Reg. Linear & $0,001^{\text {ns }}$ & $0,010^{\text {ns }}$ & $19,25^{\text {ns }}$ & $17,55^{\text {ns }}$ & $0,48^{\text {ns }}$ \\
Reg. Quadrática & $0,005^{\text {ns }}$ & $0,013^{\text {ns }}$ & $11,27^{\text {ns }}$ & $3,93^{\text {ns }}$ & $0,19^{\text {ns }}$ \\
Interação (S x D) & $0,007^{\text {ns }}$ & $0,012^{\text {ns }}$ & $4,27^{\text {ns }}$ & $1,55^{\text {ns }}$ & $0,58^{\text {ns }}$ \\
Bloco & $0,003^{\text {ns }}$ & $0,020^{\text {ns }}$ & $11,85^{\text {ns }}$ & $1,52^{\text {ns }}$ & $0,16^{\text {ns }}$ \\
CV (\%) & 10,67 & 10,15 & 6,74 & 10,17 & 6,65 \\
\hline
\end{tabular}

ns, $* * *$ respectivamente não significativo, significativo a $\mathrm{p}<0,01$ e $\mathrm{p}<0,05$ pelo teste $\mathrm{F}$; 'análise estatística realizada após transformação de dados $\mathrm{em} \sqrt{X}$

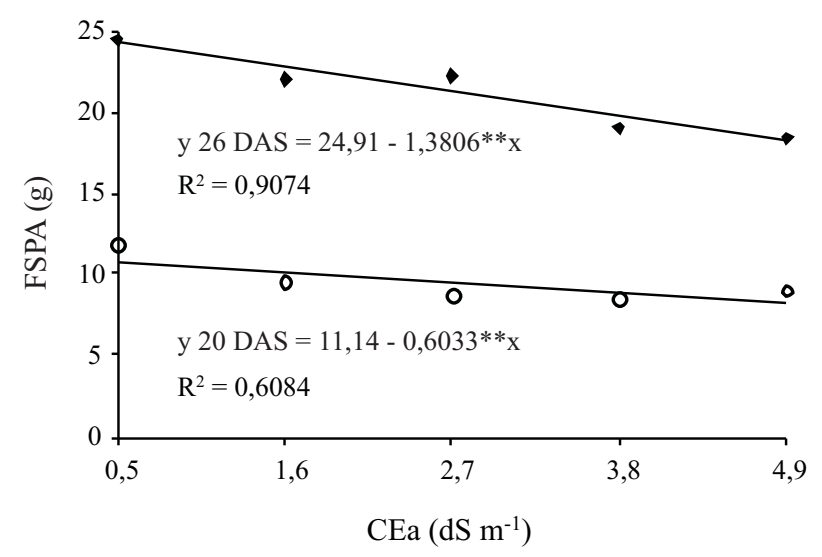

Figura 2 - Fitomassa seca da parte aérea (FSPA) de plantas de girassol, em função da condutividade elétrica da água de irrigação (CEa), aos 20 e 26 dias após semeadura (DAS)

irrigação; fato este averiguado também por Souza Junior et al. (2005) em pesquisa com algodoeiro colorido (BRS verde) sob estresse salino.

Segundo Flowers (2004) a inibição do crescimento de plantas sob estresse salino pode ser explicada pela diminuição do potencial osmótico da solução do solo, além da possibilidade de ocorrência de toxicidade iônica, desequilíbrio nutricional ou ambos, em função da acumulação em excesso de determinados íons nos tecidos vegetais. Outrossim, as plantas tendem a fechar os estômatos para reduzir as perdas de água por transpiração, resultando em uma menor taxa fotossintética, e contribuindo para redução do crescimento das espécies sob tal estresse.

O aumento do nível de salinidade da água de irrigação afetou de forma significativa $(p<0,05)$ o início do florescimento das plantas de girassol (TAB. 3). Conforme equação de regressão (FIG. 3) houve acréscimo linear de 0,73 dias por aumento unitário da $\mathrm{CEa}\left(\mathrm{dS} \mathrm{m}^{-1}\right)$ para as

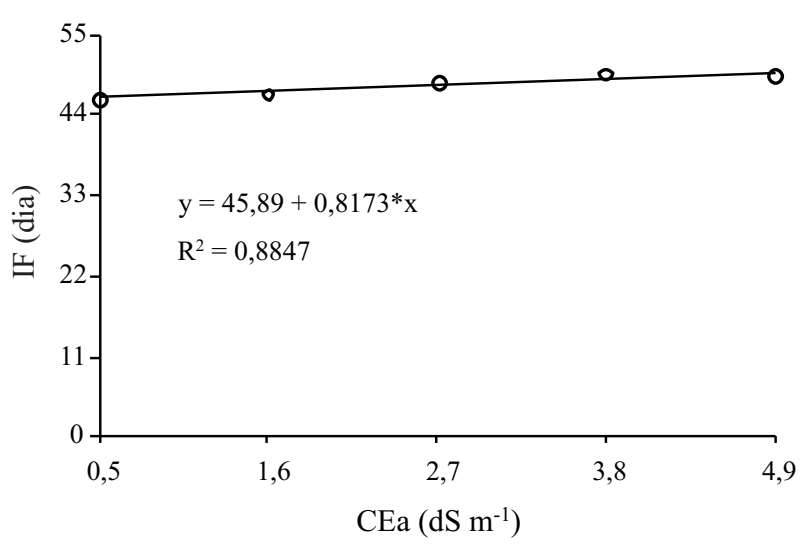

Figura 3 - Início de florescimento (IF) de plantas de girassol, em função da condutividade elétrica da água de irrigação (CEa) 
plantas iniciarem a floração, ou seja, entre os níveis de salinidade $\mathrm{S}_{1}$ e $\mathrm{S}_{5}$ houve retardamento de aproximadamente três dias e meio. Costa et al. (2008) verificaram que o aumento unitário da $\mathrm{CEa}\left(\mathrm{dS} \mathrm{m} \mathrm{m}^{-1}\right)$ retardou o floração do Amaranthus spp em meio dia.

Constata-se no presente estudo que IF em função dos tratamentos ocorreu entre $46,3\left(\mathrm{~S}_{1}\right)$ e $49,9\left(\mathrm{~S}_{5}\right)$ dias após o semeio. Segundo Embrapa (2006) a cultivar Embrapa 122/V2000 é indicada para região sul e central do Brasil, e o início do florescimento deve ocorrer aos 53 DAS; já nas condições em que foi desenvolvida esta pesquisa, vê-se (FIG. 3) que até a utilização de CEa de 4,9 dS m${ }^{-1}$ obteve-se IF inferior ao citado pela Embrapa. Esta divergência no IF ocorreu, possivelmente, devido às condições climáticas locais.
Observam-se na Tabela 3 que o fator salinidade da água de irrigação teve efeito significativo $(\mathrm{p}<0,01)$ sobre os diâmetros externo e interno de capítulo. Verificase conforme equações de regressão, resposta linear decrescente com o aumento da CEa sobre o DCe e DCi (FIG. 4A e 4B), onde constata-se decréscimo de 4,1 e $7,6 \%$ respectivamente, no diâmetro de capítulo externo e interno por aumento unitário da $\mathrm{CEa}\left(\mathrm{dS} \mathrm{m} \mathrm{m}^{-1}\right)$. Entre o nível $\mathrm{S}_{1}$ e $\mathrm{S}_{5}$ houve redução do $\mathrm{DCe}$ de $18,0 \%$ e no DCi de 33,5\%. Segundo Tester e Davenport (2003) a redução do potencial osmótico da solução do solo provocada pelo sal, dificulta a entrada de água nas células da planta e consequentemente prejudica o desempenho da cultura.
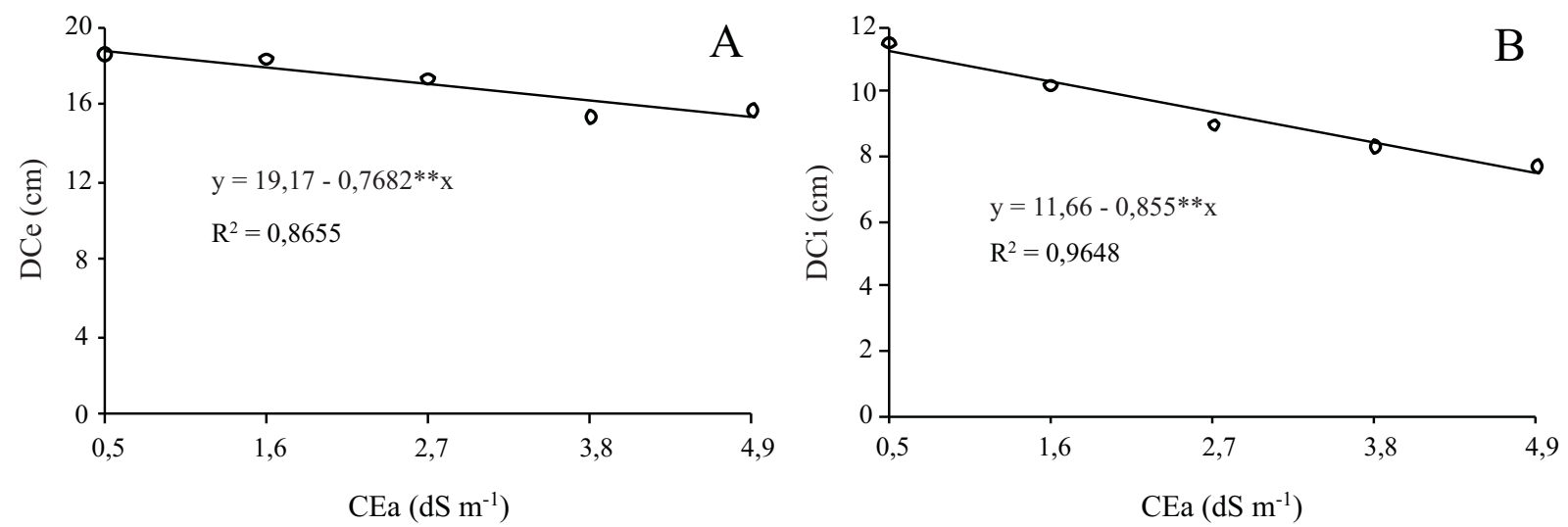

Figura 4 - Diâmetro de capítulo externo - DCe (A) e interno - DCi (B) de plantas de girassol, em função da condutividade elétrica da água de irrigação (CEa)

O diâmetro do capítulo tem implicação direta sobre o número potencial de aquênios e de acordo com Silva et al. (2009), baixos rendimento em girassol ocorrem em função da redução da disponibilidade hídrica no solo, afetando o crescimento dos capítulos e aquênios. Denota-se no presente estudo que o aumento da $\mathrm{CEa}$ possa ter provocado a redução da disponibilidade de água para as plantas e como consequência ficou evidenciado a redução do diâmetro do capítulo, sendo que, este efeito foi mais expressivo para o $\mathrm{DCi}$, ou seja, no local onde são formado os aquênios.

\section{Conclusões}

1. A altura de planta, o diâmetro caulinar, a fitomassa seca da parte aérea, o início do florescimento e os diâmetros de capítulo externo e interno do girassol cv. Embrapa
122/V-2000 são afetados linear e negativamente pela salinidade da água a partir de $0,5 \mathrm{dS} \mathrm{m}^{-1}$;

2.O girassol cv. Embrapa 122/V-2000 na presença de vermicomposto, não responde às doses de nitrogênio;

3.O efeito interativo (salinidade da água $\mathrm{x}$ doses de nitrogênio) não foi significativo para nenhuma variável estudada, indicando comportamento semelhante de doses de nitrogênio dentro da salinidade da água;

4. Dentre as variáveis estudadas, o diâmetro interno de capítulo é a mais sensível a salinidade da água.

\section{Agradecimentos}

Ao Conselho Nacional de Pesquisa e Desenvolvimento - CNPq, pela concessão do auxílio financeiro e bolsa PDJ, ao 
primeiro autor, para realização deste trabalho; ao Instituto de Ciências e Tecnologia em Salinidade - INCTSal; e a Embrapa, unidade Soja, escritório de negócios de Dourados, MS pelo fornecimento das sementes de girassol.

\section{Referências}

ASHRAF M.; HARRIS, P. J. C. Potential biochemical indicators of salinity tolerance in plants. Plant Science, v. 166, n. 01 , p. 3-16, 2004.

AYERS, R. S.; WESTCOT, D. W. A qualidade de água na agricultura. 2. ed. Campina Grande: UFPB, 1999, 153 p. (FAO, Irrigação e Drenagem, 29).

BISCARO, G. A. et al. Adubação nitrogenada em cobertura no girassol irrigado nas condições de Cassilândia-MS. Ciência e Agrotecnologia, v. 32, n. 05, p. 1366-1373, 2008.

BOSCO, M. R. de O. et al. Influência do estresse salino na composição mineral da berinjela. Revista Ciência Agronômica, v. 40 , n. 02 , p. $157-164,2009$.

CARVALHO, D. B. de; PISSAIA, A. Cobertura nitrogenada em girassol sob plantio direto na palha: I - Rendimento de grãos e seus componentes, índice de colheita e teor de óleo. Scientia Agraria, v. 03, n. 01-02, p. 41-45, 2002.

CAVALCANTI, M. L. F. et al. Crescimento inicial da mamoneira submetido à salinidade da água de irrigação. Revista de Biologia e Ciência da Terra, v. 04, n. 01, p. 1-8, 2004.

COELHO, M. A.; SONCIN, N. B. Geografia do Brasil. São Paulo: Moderna, 1982. 368 p.

CONNOR, J. D.; HALL, A. J. Sunflower physiology. In: SCHNEIDER, A. A. (Ed.). Sunflower technology and production. Madison: ASA/CSSA/SSSA, 1997. p. 113-181. (Series of monographs, 35).

COSTA, D. M. A. da. et al. Crescimento e desenvolvimento do amaranto (Amaranthus spp.) sob estresse salino e cobertura morta. Revista Brasileira Ciência do Solo, v. 32, n. 01, p. 43-48, 2008.

DEBOUBA, M. et al. $\mathrm{NaCl}$ stress effects on enzymes involved in nitrogen assimilation pathway in tomato "Lycopersicon esculentum" seedlings. Journal of Plant Physiology, v. 163, n. 12, p. 1247-1258, 2006.

EMPRESA BRASILEIRA DE PESQUISA AGROPECUÁRIA (EMBRAPA). Manual de métodos de análise de solo. 2. ed. Rio de Janeiro: Centro Nacional de Pesquisa de Solos, 1997. 212 p.

EMPRESA BRASILEIRA DE PESQUISA AGROPECUÁRIA (EMBRAPA). Girassol Embrapa 122/V-2000. Londrina, 2006. (Folder n. 04/2006).

FERREIRA, D. F. SISVAR 4.6 sistema de análises estatísticas. Lavras: UFLA, 2003. 32 p.

FLORES, P. et al. Response to salinity of tomato seedlings with a split-root system: Nitrate uptake and reduction. Journal of Plant Nutrition, v. 25, n. 01, p. 177-187, 2002.
FLOWERS, T. J. Improving crop salt tolerance. Journal of Experimental Botany, v. 55, n. 396, p. 307-319, 2004.

INSTITUTOBRASILEIRODEGEOGRAFIAEESTATÍSTICA (IBGE). Levantamento sistemático da produção agrícola (LSPA) mês agosto 2009. Disponível em: <http://www.sidra. ibge.gov.br/bda/prevsaf $/$ default.asp? $\mathrm{t}=2 \& \mathrm{z}=\mathrm{t} \& \mathrm{o}=23 \& \mathrm{u} 1=1 \& \mathrm{u} 2$ $=1 \& u 3=1 \& u 4=1>$. Acesso em: 04 out. 2009.

MARSCHNER, H. Mineral nutrition of higher plants. 3. ed. London: Academic Press, 2002. 889 p.

MILLER, A. J.; CRAMER, M. D. Root nitrogen acquisition and assimilation. Plant and Soil, v. 274, n. 01, p. 3-6, 2004.

NERY, A. R. et al. Crescimento do pinhão-manso irrigado comáguas salinas em ambiente protegido. Revista Brasileira de Engenharia Agrícola e Ambiental, v. 13, n. 05, p. 551-558, 2009.

NOBRE, R. G.. et al. Crescimento do girassol irrigado com água residuária e adubação orgânica. Revista DAE, v. 03, p. 50-60, 2009.

NOVAIS R. F.; NEVES J. C. L.; BARROS N. F. Ensaio em ambiente controlado. In: OLIVEIRA A. J. et al. (Ed.) Métodos de pesquisa em fertilidade do solo. Brasília: Embrapa-SEA, 1991. p. 189-253.

OLIVEIRA, A. M. de et al. Irrigação com água salina no crescimento inicial de três cultivares de algodão. Irriga, v. 13, n. 04, p. 467-475, 2008.

OLIVEIRA, M. K. T. et al. Efeito de diferentes teores de esterco bovino e níveis de salinidade no crescimento inicial da mamoneira (Ricinus communis L.). Revista Verde, v. 01, n. 01, p. 47-53, 2006.

RICHARDS, L. A. Diagnosis and improvement of saline and alkali soils, Washington: U.S, Department of Agriculture, 1954. 160 p. (USDA, HandBook, 60).

SILVA, A. G. da. et al. Desempenho de híbridos de girassol em espaçamentos reduzidos. Semina: Ciências Agrárias, v. 30 , n. 01, p. 31-38, 2009.

SOUZA JUNIOR, S. P. et al. Germinação, crescimento e produção do algodoeiro colorido BRS verde sob estresse salino. Revista Brasileira de Engenharia Agrícola e Ambiental, v. 9, p. 236-241, 2005. Suplemento.

STEPPUHN, H. Pre-irrigation of a severely-saline soil with in situ water to establish dry land forages. Transactions of the ASAE, v. 44, n. 06, p. 1543-1551, 2001.

TESTER, M.; DAVENPORT, R. Na ${ }^{+}$tolerance and $\mathrm{Na}^{+}$transport in higher plants. Annals of Botany, v. 91, n. 03, p. 503-527, 2003.

TRAVASSOS, K. D. et al. Crescimento inicial do girassol sob estresse salino. In: CONGRESSO BRASILEIRO DE ENGENHARIA AGRÍCOLA, 38., 2009, Juazeiro-BA/PetrolinaPE. Anais... Juazeiro-BA/Petrolina-PE: SBEA, 2009. 4 p.

UNGARO, M. R. G. Potencial da cultura do girassol como fonte de matéria-prima para o programa nacional de produção e uso de biodiesel. In: CAMARA, G. M.; HEIFFIG, L. S. (ed.) Agronegócio de plantas oleaginosas: matérias-primas para o biodiesel. Piracicaba: ESALQ, 2006. p. 57-80. 